\title{
Costing the ex situ conservation of plant genetic resources at AVRDC - The World Vegetable Center
}

\author{
Pepijn Schreinemachers • Andreas W. Ebert • \\ Mei-Huey Wu
}

Received: 7 August 2013/ Accepted: 9 December 2013/Published online: 10 January 2014

(C) The Author(s) 2014. This article is published with open access at Springerlink.com

\begin{abstract}
AVRDC - The World Vegetable Center maintains the world's largest international public collection of vegetable genetic resources at its headquarters in Taiwan. The ex situ conservation and dissemination of germplasm to researchers and breeders worldwide contributes to global food and nutrition security but also carries considerable costs. The objective of this study is to quantify these costs for the 12-month period from September 2011 to August 2012 using the Decision Support Tool developed by the International Food Policy Research Institute. The results show that the present value of capital assets is USD 1.99 million for the facilities and USD 0.48 million for the equipment. The total annual cost is USD 0.684 million, of which $74 \%$ are labor costs. The average conservation and dissemination cost per accession is USD 10.08 per year. Seed regeneration, seed processing, characterization, and seed dissemination are the four most costly operations of the genebank. The storage itself only contributes $17 \%$ of the cost. In comparison, the average cost per accession is USD 5.15 at ICARDA, USD 6.84 at CIMMYT, USD 8.62 at ICRISAT, USD 9.19 at IRRI, and USD 22.52 at CIAT (in 2012 US dollar values). High labor costs in Taiwan increase AVRDC's average cost, but the fact that more vegetable species are selfpollinating and thus less labor intensive to regenerate
\end{abstract}

P. Schreinemachers $(\varangle) \cdot$ A. W. Ebert · M.-H. Wu AVRDC - The World Vegetable Center, P.O. Box 42, Shanhua, Tainan 74199, Taiwan

e-mail: Pepijn.schreinemachers@worldveg.org than cross-pollinating species keeps the average costs in check. These results are important benchmarks for other genebanks.

Keywords Agricultural biodiversity ·

Economics · Genebank · Genebank management ·

Germplasm · Vegetable genetic resources

\section{Introduction}

Crop genetic diversity, created through natural and human selection over millennia and complemented by the diversity present in wild relatives of crop plants, provides the raw material that can be employed by scientists to improve crop productivity and diversify production systems. But genetic variation, once considered unlimited, is fast eroding as modern breeding lines replace traditional cultivars over large areas (Stamp et al. 2012), and natural habitats are increasingly destroyed through human intervention (UNEP 2011; WWF 2010).

Plant genetic resources need to be preserved to combat evolving and rapidly emerging new strains of pests and diseases, and to produce varieties that are better-adapted to changing climatic and environmental conditions and produce stable yields under such changing conditions (FAO 2010). To provide the necessary building blocks for scientists and breeders to 
successfully develop improved and well-adapted varieties, genebank personnel engage in the collection, assembly, maintenance and conservation, characterization, documentation, and distribution of germplasm for research and development.

The collection of germplasm at AVRDC - The World Vegetable Center provides breeders worldwide with a broad genetic base for vegetable breeding (Keatinge et al. 2008). The collection harbors a range of desirable traits such as resistance to pests and diseases and tolerance to adverse climatic conditions as well as traits for improving the nutritional quality of vegetable crops (Ebert 2011). Many of the accessions are local landraces, wild relatives of cultivated crops, and indigenous varieties that are being lost as farmers adopt new high yielding varieties of high value vegetable crops. Their preservation and their availability for utilization in research and breeding are of utmost importance to ensure future food and nutrition security of a rapidly growing population (FAO 2010; McCouch 2013). Landraces and crop wild relatives are increasingly valued and exploited for genes that provide increased biotic resistance, tolerance to abiotic stress, and improved yield and quality (Jackson et al. 2007; Frison et al. 2011). These genetic resources, which are threatened by human intervention and climate change are the raw materials that are needed to improve the capacity of crops to respond to climate change and other future challenges and to secure nutritious food for a growing world population (FAO 2010).

With 67,817 accessions and sub-accessions or 60,347 original accessions presently in its collections, the AVRDC genebank is the fifth largest international public genebank in the world. Only the International Crops Research Institute for the Semi-Arid Tropics (ICRISAT) (156,313), the International Maize and Wheat Improvement Center (CIMMYT) $(155,129)$, the International Center for Agricultural Research in the Dry Areas (ICARDA) (134,160 accessions), and the International Rice Research Institute (IRRI) $(110,817)$ hold larger collections (2009 data). AVRDC holds its vegetable germplasm collection in trust for the global community and is committed to ensuring its long-term conservation and unrestricted availability. The genebank distributes annually close to 7,000 germplasm accessions and breeding lines to about 70 countries worldwide. To ensure compliance with the principles and regulations of the International Treaty on Plant Genetic Resources for Food and Agriculture, AVRDC adopted the Food and Agriculture Organization Standard Material Transfer Agreement on 1 August 2013.

The ex situ conservation and dissemination of vegetable genetic resources provides enormous benefits to the world's population by supplying a diverse range of vegetable germplasm to crop breeding programs worldwide. Yet such an effort comes at a considerable cost, for which sustained funding is required. The objective of this study is to quantify the full cost of vegetable germplasm conservation and dissemination. A complete understanding of operating costs is important for the effective management of the genebank. Making the cost structure public is also important for other genebanks, as they can use it as a benchmark to compare with their own cost structure.

Koo et al. (2002, 2003a, 2003b, 2004) developed a methodology for costing genebank operations based on accounting principles. Using data from five centers of the Consultative Group on International Agricultural Research (CGIAR) containing $87 \%$ of the accessions held by the CGIAR, they estimated that the cost of storing an accession for 1 year is about USD 1.50 for most crops. They also estimated that the cost of conserving and distributing the CGIAR collection is USD 5.7 million per year and suggested that an endowment of USD 149 million invested at an average annual interest rate of $4 \%$ would probably be sufficient to conserve the germplasm collections in perpetuity. Based on the same methodology, Horna (2010) developed a Decision Support Tool (DST) for genebank costing studies, which is what we applied in this study.

The paper provides some relevant background information about the germplasm collection at AVRDC and then describes the methodology used. After presenting the results, we discuss how the cost structure compares to the major genebanks of the CGIAR and the challenges for maintaining the collection.

\section{The germplasm collection at AVRDC}

History of the collection

Founded in 1971 as the Asian Vegetable Research and Development Center with headquarters in Shanhua, 
Taiwan and a mandate to enhance vegetable production in the Asian tropics, AVRDC - The World Vegetable Center, as it is called now, has taken up a global role in promoting and supporting vegetable research and development in Africa, Asia, and other regions of the world. AVRDC's mission is to alleviate poverty and malnutrition in the developing world through the increased production and consumption of nutritious and health-promoting vegetables. AVRDC's genebank plays a central role in achieving this mission through the provision of diverse germplasm with a wide range of desirable traits such as resistance to pests and diseases, tolerance to adverse climatic conditions as well as traits for improving the nutritional quality of vegetable crops, both to its own scientists and vegetable breeders and to public and private sector breeders and researchers worldwide.

Realizing the need to support AVRDC's vegetable breeders with diverse germplasm for effective crop improvement, a Seed Laboratory Unit was established at AVRDC headquarters in 1975 and 10 years later (1985), the current Genetic Resources and Seed Unit (GRSU) laboratory was designed and constructed to properly house and conserve the growing germplasm collection. From 1992 onwards, AVRDC also established an active collection and medium-term storage facilities at its Regional Center for Africa in Arusha, Tanzania.

Growth in the number of accessions conserved and distributed

Soon after the founding of AVRDC in 1971, the Center started off in 1972 with a modest collection of 590 accessions of three crop groups: Brassicas, tomato and legumes, mainly Vigna species. By 1995, the genebank had grown to 43,205 accessions, comprising 63 genera and 209 species. To date, it has accumulated 67,817 accessions and sub-accessions or 60,481 original accessions comprising 171 genera and 438 species from 156 countries of origin, a growth of $40 \%$ in number of accessions, $171.4 \%$ in number of genera, and $109.6 \%$ in number of species during the last 18 years.

The long-term objective of AVRDC's genebank is to assemble, conserve and utilize comprehensive collections of its principal crops such as soybean, tomato, pepper, mungbean, eggplant, Brassica, alliums, and cucurbits. Germplasm enhancement through morphological and molecular characterization, screening for biotic and abiotic stress tolerance, and appropriate documentation provides better services to AVRDC's breeders as well as to breeders and scientists worldwide. We note that germplasm screening, evaluation and other pre-breeding and breeding activities are undertaken by research units other than the genebank and these are therefore not included in this costing study.

AVRDC maintains several of the world's largest vegetable collections held by a single institution (Ebert 2013), such as sweet and hot pepper (Capsicum spp.; 8,170 accessions), tomato (Solanum spp.; 8,150) and eggplant (Solanum spp.; 3,702). Other major AVRDC collections are soybean (Glycine spp.; 15,321), mungbean (Vigna radiata (L.) R. Wilczek var. radiata and $V$. radiata (L.) R. Wilczek var. sublobata (Roxb.) verdc.j 6,737), Azuki bean (Vigna angularis (Willd.) Ohwi and V. Vigna angularis (Willd.) Ohwi et H. Ohashi var. nipponensis (Ohwi) Ohwi et H. Ohashi; 2,376), Brassica spp. (1,909), Vigna unguiculata (L.) Walp. with several subspecies (cowpea, yard-long bean; 1,570), and Allium spp. $(1,129)$. AVRDC also holds a global collection of more than 10,000 indigenous vegetables from South Asia, Southeast Asia, and Africa (de la Peña et al. 2011), and approximately 200 new accessions are added each year in cooperation with national agricultural research and extension programs and national, regional, and international genebanks.

AVRDC actively exchanges genetic resources and related information with national programs, regional organizations, and the private sector. Each year 6,000-7,000 accessions and breeding lines are distributed for crop improvement programs and related research. The seed samples go to AVRDC scientists $(37 \%)$, national agricultural research and extension systems (26\%), private sector seed companies $(22 \%)$, universities $(10 \%)$, nongovernmental organizations (3\%), and others $(2 \%)$ (2012 data).

Since its founding, the AVRDC genebank has distributed close to 590,000 seed samples $(253,363$ accessions) to researchers and breeders in 200 countries (as of March 2013). These figures exclude accessions deposited at other genebanks like the National Plant Genetic Resources Center (NPGRC) of the Taiwan Agricultural Research Institute in Taiwan which are not covered by a black-box 
agreement. ${ }^{1}$ This means that such deposits form part of the active collection of the receiving genebank and can be distributed independently, without the need to inform the donor genebank.

Thanks to long-term breeding efforts focusing on several major vegetable crops, more than 466 improved vegetable varieties developed from the germplasm held by AVRDC have been released to farmers around the world, helping them to produce good harvests and generate income despite pest and disease pressure or abiotic stress (Mecozzi and Ebert 2012). Genebank accessions of various crops, such as tomato, sweet and hot pepper, vegetable soybean, mungbean, and yard-long bean were selected for competitive, multi-location yield trials in several countries and subsequently released without involvement of AVRDC. Out of 34 new vegetable varieties released in Central Asia and the Caucasus from 2007 to 2012, 13 varieties (38\% of total) originated from the AVRDC genebank (AVRDC 2013).

\section{Current genebank facilities and operations}

To safeguard its valuable collection, AVRDC embarked on an extensive renovation and expansion of its 28-year-old genebank building during the period from 2009 to 2011 . The current facility has enough space to nearly double the current collection.

AVRDC maintains base, active, and working collections. Most accessions are held in both base and active collections. Base collections are kept in long-term storage conditions in laminated aluminum polyethylene pouches at -16 to $-18{ }^{\circ} \mathrm{C}$. Active collections used for internal and external seed distribution and other research are kept in medium-term storage conditions at $5{ }^{\circ} \mathrm{C}$ and $40-45 \%$ relative humidity (RH), while working collections are kept in short-term storage conditions at $15{ }^{\circ} \mathrm{C}$ and $40-45 \%$ RH. AVRDC staff members routinely determine the initial viability of seed samples before the samples are moved into medium- and long-term storage. This information is used to predict longevity of seeds in storage and to schedule viability monitoring tests and regeneration needs.

\footnotetext{
${ }^{1}$ A black-box arrangement is a security backup storage agreement in which the receiving genebank provides storage but does not conduct viability tests or distribute seed, and will return seed to the owner upon request.
}

AVRDC has about 100 ha of experimental fields, out of which the genebank uses approximately 7 ha annually for seed regeneration. Moreover, the Genetic Resources and Seed Unit has seed processing facilities for seed extraction, cleaning, drying, and packing; and laboratory facilities for morphological characterization, viability testing, tissue culture for embryo rescue and maintenance of virus-cleaned material, and seed health inspection. While seed of most vegetable crops produce orthodox seed, which can be dried to low moisture content and stored at sub-zero temperatures, vegetatively (asexually) propagated crops such as shallot (Allium cepa L. var. aggregatum G. Don; 30 accessions) and garlic (Allium sativum L. var. sativum; 262 accessions) are held in field genebanks. Accessions of Moringa spp., a tree, the leaves of which are eaten as vegetable, are kept in a field genebank (44 accessions) as well as in a seed collection (59 accessions).

Slow drying is accomplished in a dehumidifying room at $18{ }^{\circ} \mathrm{C}$ and $10-15 \% \mathrm{RH}$. Seed stored for longterm conservation are sealed in aluminum foil pouches to maintain seed moisture content at 4-7\%. There are two post-entry quarantine screenhouses for newly collected material. All outgoing material passes through the Bureau of Animal and Plant Health Inspection and Quarantine of the Council of Agriculture, Taiwan, which issues a phytosanitary certificate. The genebank also serves as a clearinghouse for other germplasm distributed by AVRDC, mainly the advanced breeding lines that the Center's breeding units release for multilocational testing. Each germplasm sample intended for distribution is closely monitored and processed for quarantine purposes. AVRDC strictly follows the quarantine regulations of the host country and recipient countries.

During multiplication, plants are kept inside net cages to prevent cross-fertilization, thus maintaining the genetic integrity of the accessions. Genebank activities are conducted using standard protocols following internationally recognized best practices (FAO 2013). AVRDC has developed appropriate protocols for germplasm regeneration and storage of indigenous vegetables and other crops that do not have documented standard practices.

Smooth management of the genebank demands meticulous recordkeeping. The AVRDC Vegetable Genetic Resources Information System facilitates the recording, storage and maintenance of germplasm 
data. It links all operations associated with germplasm conservation and management, from registration, characterization, evaluation, seed inventory, and seed distribution to end-users. ${ }^{2}$

Parts of AVRDC's germplasm collection have been duplicated at other genebanks, including the National Plant Genetic Resources Center, Taichung, Taiwan (26,954 accessions); National Plant Genetic Resources Laboratory (NPGRL), Institute of Plant Breeding, Los Baños, the Philippines (4,853 mungbean (Vigna radiata) and 4,554 tomato (Solanum spp.) accessions); National Institute of Agrobiological Sciences, Tsukuba, Japan (Southeast Asian soybeans (Vigna spp.), 2,389 accessions; Brassica spp., 357 accessions); the United States Department of Agriculture-Agricultural Research Service, Fort Collins, USA (Southeast Asian soybeans (Vigna spp.), 2,389 accessions); National Vegetable Research Station, Wellesbourne, UK (Brassica spp., 371 accessions). ${ }^{3}$

In 2008, AVRDC concluded a black-box arrangement with the Nordic Genetic Resource Center in Norway, which is responsible for the operation and management of the Svalbard Global Seed Vault. Three deposits have been made at Svalbard, now reaching a total of 12,769 accessions. Also in 2008, AVRDC concluded a third black box arrangement for safety backup of part of the collection with the genebank of the National Agrobiodiversity Center of the Rural Development Administration (RDA) in South Korea. This genebank has been recognized by the Global Crop Diversity Trust as a facility for the safekeeping of duplicates of collections of crop genetic resources of regional and global importance (RDA 2008). A total of 12,819 accessions have been deposited at the RDA genebank.

\section{Methodology}

For this study we used the DST developed by the International Food Policy Research Institute within the context of the Systemwide Genetic Resources

\footnotetext{
The AVGRIS website is available at http://203.64.245.173/ index.asp.

${ }^{3}$ With the exception of the vegetable genebank in Wellesbourne, no black-box arrangements were made for these duplicates and accessions simply became part of the managed collection of the recipient genebank.
}

Programme (Horna 2010). We started with version v1.1 of the tool, which has an Excel-based interface with some of the calculations performed using visual basic for applications (VBA). We adjusted the tool to add more crops and implemented all VBA formulas directly in the Excel workbook to have more control over the calculations.

The DST is based on a production economics framework that considers a genebank as a production entity that turns inputs (facilities, labor, variable inputs) into outputs (accessions conserved and distributed). The DST quantifies monetary costs based on historical data but does not quantify the benefits accruing from the conservation of plant genetic resources, as these depend on a largely unpredictable demand for genetic resources in the future.

The DST conceptualizes a genebank for plant genetic resources to perform fifteen operations, including: (1) Management: data and information management and general administration; (2) Conservation: acquisition of new accessions, seed multiplication/ regeneration, characterization, safety duplication, long-term storage, cryopreservation, in vitro conservation, viability (germination) testing, seed processing and seed health testing; and (3) Distribution: mediumterm storage and dissemination. The costs of some of these operations (e.g. storage) accrue annually, while other costs (e.g. regeneration) only occur periodically.

The DST separates between four types of monetary costs listed in Table 1. The distinction between fixed, quasi-fixed and variable (labor and non-labor) costs allows calculating average and marginal costs per accession and the consideration of possible economies of scale as fixed costs can be spread over a larger number of accessions (Pardey et al. 2001).

The tool can furthermore break the total costs down into operations and crops and, for instance, estimate the cost of storing one additional tomato accession for 1 year or in perpetuity. To do this, the tool requires each cost item in Table 1 to be allocated to operations (using weights) and crops (by indicating if it was used on the crop or not). In addition, the tool needs data on (1) the number of accessions per crop and per operation; (2) the genebank facility area per crop and per operation; and (3) the frequency of repeating operations (e.g. once, yearly, every 10 years). If a cost item cannot be allocated to a specific crop or operation, then the tool distributes it evenly over all accessions. 
Table 1 Cost categories in the decision support tool (DST)

\begin{tabular}{|c|c|c|}
\hline Cost type & Definition & Data required \\
\hline Capital costs & $\begin{array}{l}\text { Present value of the capital stock (facilities and } \\
\text { equipment) that is independent of the size of } \\
\text { operations such as buildings, laboratory } \\
\text { equipment, computers, and furniture }\end{array}$ & $\begin{array}{l}\text { The purchase cost, the purchase year and (expected) } \\
\text { service life for each stock item. All prices are } \\
\text { converted to current nominal values using the } \\
\text { consumer price index (CPI), annualized using the } \\
\text { discount rate, and converted to US dollars using } \\
\text { the current exchange rate }\end{array}$ \\
\hline Quasi-fixed costs & Cost of all scientific and permanent staff & $\begin{array}{l}\text { Annual salaries, insurance premiums, pension } \\
\text { contributions and all other benefits but excluding } \\
\text { indirect costs }\end{array}$ \\
\hline Variable labor costs & $\begin{array}{l}\text { Cost of temporary workers and others } \\
\text { such as consultants who worked within } \\
\text { a given year }\end{array}$ & $\begin{array}{l}\text { Annual salaries, insurance premiums, pension } \\
\text { contributions and all other benefits but excluding } \\
\text { indirect costs }\end{array}$ \\
\hline Non-labor variable costs & Operating expenses & $\begin{array}{l}\text { Cost of office and laboratory supplies, travel } \\
\text { expenses, electricity, water, farm inputs, etc. }\end{array}$ \\
\hline
\end{tabular}

\section{Data}

At AVRDC in Taiwan, the season for seed production starts in September and lasts until June in the subsequent year. We therefore chose the reference year to be from September 2011 to August 2012. This 12 -month period had a usual pattern of rainfall and there were no major unexpected events that affected genebank operations. We included 20 crops-each with at least 300 accessions in the genebank, and took all other crops together in the category "Minor crops".

\section{General parameters}

The AVRDC genebank started operations in 1984 and we assumed that it will operate for 200 years, which is the same duration as assumed by most other genebank costing studies in the CGIAR. All costs that occurred in the local currency (New Taiwan dollar) were converted to US dollars using the average exchange rate at the time of the purchase and then deflated to 2012 prices using the US consumer price index. ${ }^{4}$ The conversion to US dollar is justified as the Center holds its bank account in the United States and uses the US

\footnotetext{
4 The average exchange rate (09.2011-08.2012) was 29.89 NTD/USD and taken from the Central Bank of the Republic of China (Taiwan) (http://www.cbc.gov.tw/content.asp?CuItem= 1878). The US dollar consumer price index was taken from the United States Bureau of Labor Statistics (http://data.bls.gov/cgibin/surveymost?cu).
}

dollar as its accounting currency. A discount rate of $1.9 \%$ was used to calculate the present value of the genebank's assets such as its facilities. Overhead costs ( $21.3 \%$ in the 2012/2013 financial year) were added to all cost items.

\section{Accessions and operations}

Of the fifteen operations in the DST, ten were relevant for the AVRDC genebank and one new operation, short-term storage, was added to the tool. AVRDC keeps working collections of breeding lines in shortterm storage conditions at $15{ }^{\circ} \mathrm{C}$ and $40-45 \% \mathrm{RH}$. Fresh seed samples received by the genebank are also kept in these conditions until samples have been properly processed (determination of seed moisture content, viability testing and additional drying) and can be stored either in medium- or long-term conditions. Due to lack of storage space in medium-term conditions some collections, especially mungbean, soybean, and yard-long bean, are being kept for longer periods under short-term conditions. With the still ongoing transfer of germplasm from the old to the new cold rooms, these accessions will eventually move to the new facility.

AVRDC does not currently practice cryo-preservation or in vitro conservation of germplasm although facilities have been allocated and equipped to do the latter. In the past, in vitro conservation was used for the maintenance of the sweet potato collection $(1,500$ accessions); with the transfer of this collection to CIP in Peru in 1993, in vitro conservation is no longer used. 
The facility is used for embryo rescue in interspecific crosses and for the maintenance of virus-cleaned garlic and shallot lines. We allocated the cost of these facilities equally over all germplasm accessions.

In the reference year, no accessions were sent to other genebanks for safety duplication, as accessions are often accumulated over a period of two successive seasons to reduce shipment, quarantine inspection and handling costs. No specialized seed health testing was performed during the reference period by AVRDC staff. Training activities were taken together with general management as neither is specific to crops or operations.

Table 2 shows the number of accessions included in each operation during the reference year. Many accessions in the genebank have sub-accessions. This is especially the case for mungbean (Vigna radiata), but is also common for other crops. When accessions are grown out for regeneration and seed multiplication, morphological traits are closely monitored at different growth stages (seedling, vegetative state, flowering, and reproductive stage). If a group of entire plants, or their flowers, fruits or seeds show one or more clearly distinct morphological variants, the subpopulations are harvested separately and seeds are assigned one or more sub-accession numbers while maintaining the original accession number as a unique accession identifier. Sub-accessions are coded by adding a letter (A, B, C or D) to the original accession number. Each sub-accession is handled separately in all germplasm management processes (characterization, seed extraction, drying, cleaning, packing, storage, and seed safety duplication). The total number of accessions and sub-accessions managed by the curators is therefore much larger than the total number of registered original accessions.

\section{Capital costs}

The facilities of the AVRDC genebank include the main building, which was renovated and extended in 2010/2011, plastic screen houses used for seed regeneration and a multiple purpose outdoor area as shown in Table 3. The net present value of these facilities was USD 1.99 million (in 2012 prices). Other capital costs included 324 items of equipment currently in use and purchased between 1972 and 2012. Many of these items had exceeded their usual service life but were still in use. We only included equipment still within its usual service life, which gave 115 different items with a total net present value of USD 0.48 million. Purchase values were converted to US dollars at the time of purchase and then annualized using the service life and discount factor and converted to 2012 US dollar values using the consumer price index.

The annualized capital cost of the AVRDC genebank, as shown in Table 3, is USD 106,708. Of these costs, $44 \%$ is for the maintaining the genebank building, $11 \%$ for the cooling systems, $13 \%$ for equipment and $18 \%$ for the Center's overhead.

Quasi-fixed and variable labor costs

The permanent staff of the AVRDC genebank includes a genebank manager, one secretary, one research associate, five curators, one laboratory assistant and six permanent field workers. The total cost of permanent staff was USD 376,221/year.

Variable labor costs include four field workers for planting and harvesting ("Regeneration" in the DST) and five laboratory workers who help with the seed packing ("Seed processing" in the DST). The total cost of non-permanent staff was USD 40,633/year.

Variable non-labor costs

Variable non-labor costs included 438 expense items that occurred during the reference period. The total value was USD 71,196/year. The cost of electricity was $30,408(43 \%)$. Other major items were the purchase of nylon nets for the net houses (USD 4,638), and the cost of renting land and preparation (USD $3,420)$. Each item was allocated to a certain operation by using weights, with the sum of weights being unity. As the variable cost items were difficult to allocate to specific crops, this was done based on the relative number of accessions for each crop in the genebank.

\section{Results}

Total annual cost

The total annual cost of conserving and distributing the germplasm collections at AVRDC in Taiwan is USD 683,548 as based on the annual cost in the reference year. Figure 1 shows the cost structure. Note that for this and all subsequent figures, we included the 


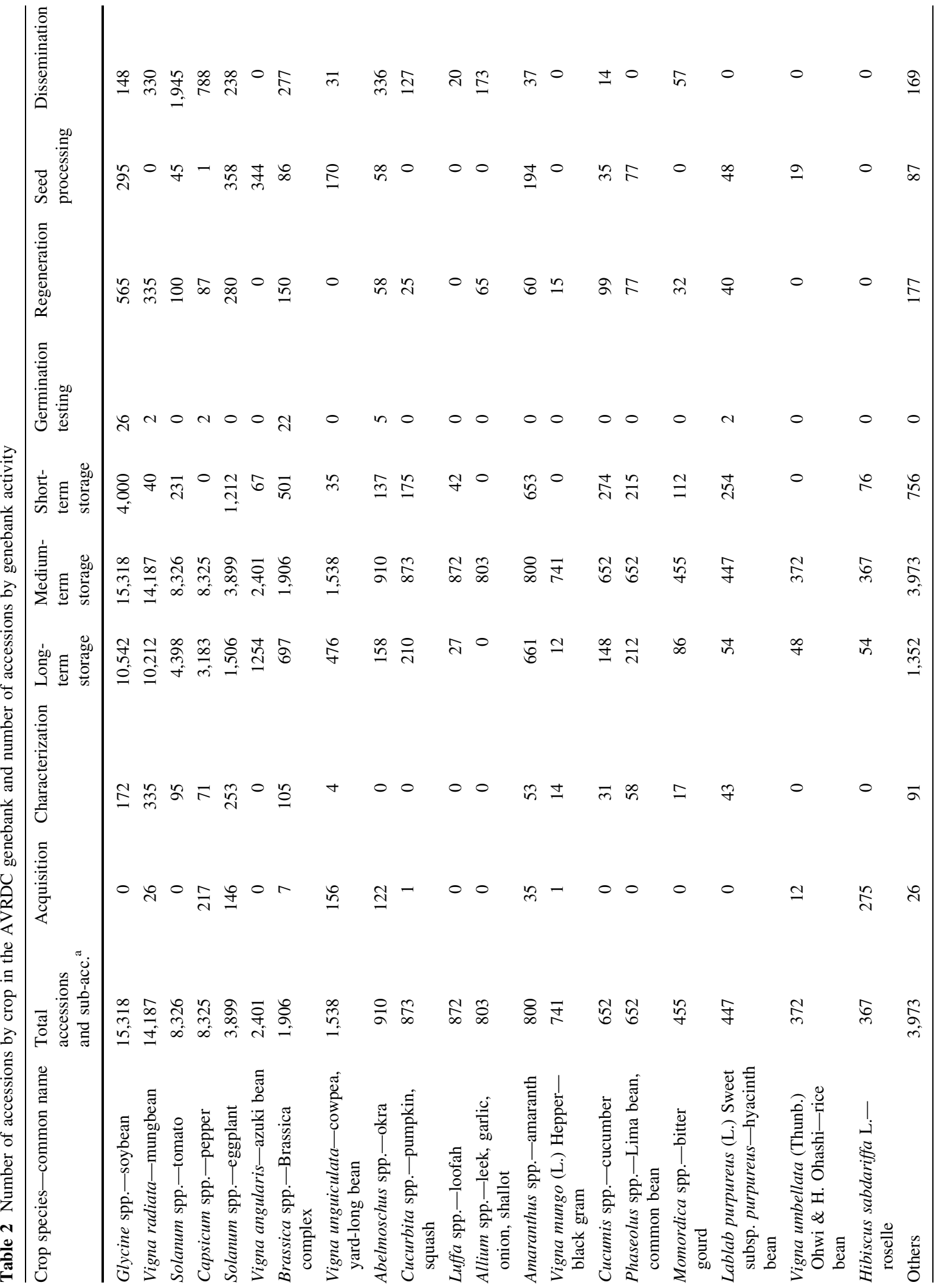


overhead costs $(21.3 \%)$ in each category and do not show them separately. Of the annual cost, $15.6 \%$ is annualized capital cost of the genebank assets and $66.8 \%$ is quasi-fixed permanent labor cost. Permanent and temporary labor together contributes $74 \%$ of the annual cost of the genebank. The operation using the most labor resources is seed regeneration $(23.3 \%$ of the total labor costs) while seed processing, characterization, germplasm dissemination, and general management each contribute to about $12-14 \%$ of the labor costs.

Figure 2 shows the annual cost by genebank operation. Seed regeneration and seed processing are the two most costly operations, followed by dissemination, general management and characterization. In comparison, the cost of keeping germplasm in long-, medium- or short-term storage is relatively low. Combined, these three storage operations account for $17 \%$ of the annual cost of the genebank.

Figure 3 distributes the annual cost of the genebank to the 20 main collections, plus the category "Minor crops" for those with less than 300 accessions. Glycine spp. (soybean), Vigna radiata (mungbean), Solanum spp. (eggplant and tomato) and Capsicum spp. (pepper) are the most costly accessions to maintain and to distribute, yet these are also the five largest collections of the genebank. Collections with a greater number of accessions also have higher total costs; in fact, the pairwise correlation coefficient between these two variables is $0.91(p<0.01)$. This correlation is not surprising as the DST allocates costs based on the number of accessions if not specified otherwise by the user. We return to this in the discussion section.

Average cost per accession

To better understand the costs of the various genebank operations Table 4 shows the total cost per operation and average cost per accession in the reference year. The table shows that germination testing was the most expensive operation at USD 104.1 per processed accession, but it was done for only 59 accessions in the reference year. Recent genebank data suggest that the first germination monitoring tests could be delayed from the currently recommended 5-10 year interval to 25 years after regeneration (van Treuren et al. 2013), thus greatly reducing the per accession cost of this activity. Regeneration, seed processing and characterization are also relatively expensive per processed 
Table 3 Facilities and equipment of the AVRDC genebank

\begin{tabular}{|c|c|c|c|c|c|}
\hline Facility/equipment & $\begin{array}{l}\text { Year } \\
\text { constructed }\end{array}$ & $\begin{array}{l}\text { Service life } \\
\text { (years) }\end{array}$ & $\begin{array}{l}\text { Area } \\
\left(\mathrm{m}^{2}\right)\end{array}$ & $\begin{array}{l}\text { Replacement } \\
\text { cost (USD) }\end{array}$ & $\begin{array}{l}\text { Annualized } \\
\text { cost (USD) }\end{array}$ \\
\hline Main building (original) & 1984 & 60 & 1,027 & 780,116 & 21,494 \\
\hline Main building (renovation) & 2011 & 25 & - & 207,681 & 10,317 \\
\hline Building extension & 2010 & 60 & 422 & 547,971 & 15,098 \\
\hline Plastic screen houses & 1986 & 30 & 396 & 20,110 & 869 \\
\hline Plastic houses (original) & 1992 & 30 & 251 & 73,640 & 3,183 \\
\hline Plastic houses (renovation) & 2012 & 20 & - & 397 & 24 \\
\hline Outdoor area & 2010 & 30 & 424 & 8,652 & 374 \\
\hline Overhead cost $(21.3 \%)$ & & & & 349,015 & 10,939 \\
\hline Subtotal facilities & & & & $1,987,581$ & 62,297 \\
\hline Cooling equipment & & & & 186,584 & 11,243 \\
\hline Computer hardware & & & & 17,002 & 2,852 \\
\hline Seed processing equipment & & & & 65,891 & 8,272 \\
\hline Other equipment & & & & 122,792 & 14,281 \\
\hline Overhead cost $(21.3 \%)$ & & & & 83,553 & 7,806 \\
\hline Subtotal equipment & & & & 475,821 & 44,455 \\
\hline Total & & & & $2,463,402$ & 106,752 \\
\hline
\end{tabular}

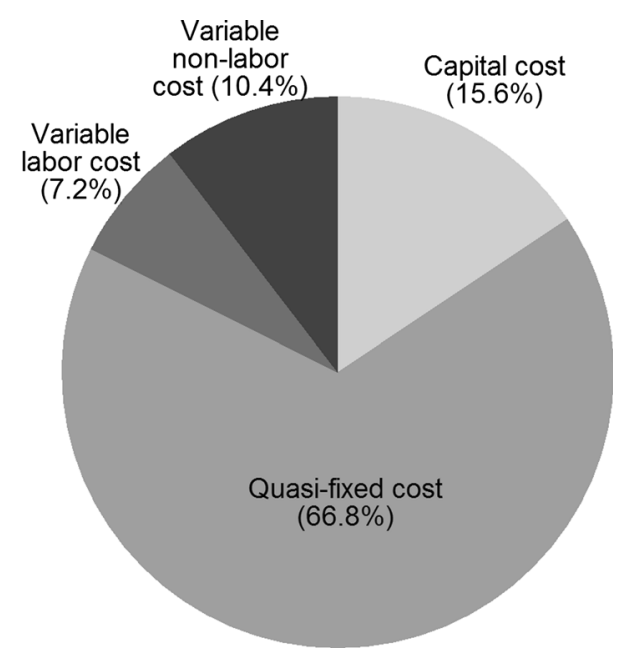

Fig. 1 Structure of the genebank's annual cost

accession at a cost of USD 64.4, USD 62.2, and USD 49.5 , respectively. The cost of germplasm dissemination was an average of USD 18.2 per distributed accession. The last column of Table 4 divides the total cost by the total number of accessions in the genebank to get the average cost per genebank accession.

It costs USD 1.73 to hold an accession for 1 year in the genebank without any special treatment, that is, the

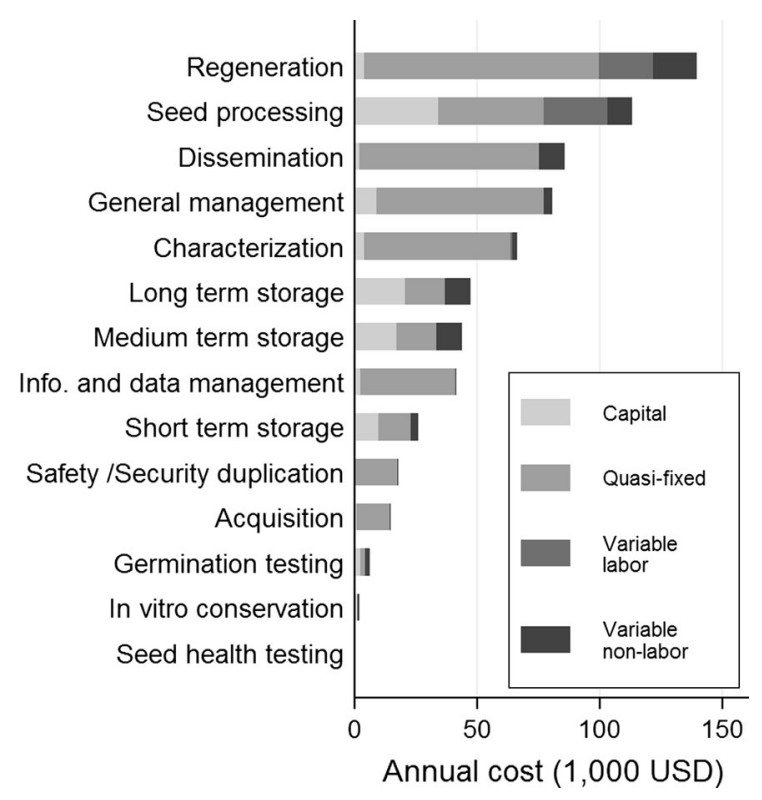

Fig. 2 Annual cost of the genebank by operation, 09/2011-08/ 2012

sum of short-, medium-, and long-term storage costs per accession. If all operations performed by the genebank are included, the cost per accession is USD 10.08. Seed regeneration, seed processing, 
Fig. 3 Total annual cost of the genebank by crop species, 09/2011-08/2012

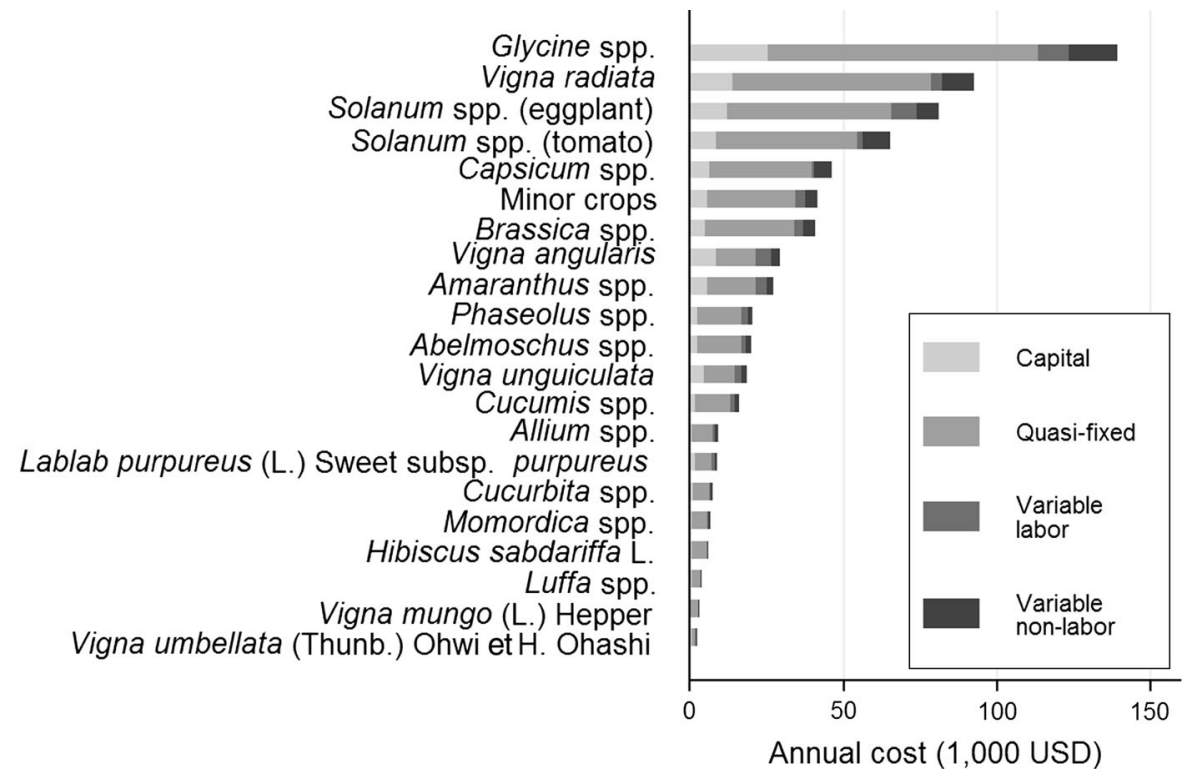

dissemination and general management are the most costly items, contributing to $61 \%$ of these costs. We note that this is not the actual cost of conserving the collection as, for instance, germination testing needs to be done more frequently as is currently the case. We return to this in the discussion.

In perpetuity costs

Previous studies have estimated the in-perpetuity value as the basis for estimating the size of a conservation endowment fund to sustain the operations of the CGIAR genebanks. Such an endowment should generate a perpetuity (that is, an annuity over an infinite period) to cover the cost of conservation and dissemination of the current germplasm collection.

The present value of such a fund can be calculated as the required annual amount of financial resources divided by the expected average real (net of inflation) interest rate. For this we assume that the cost and cost structure of the genebank would remain unchanged in real terms so that the costs observed in the reference year are representative for all future years. As this assumption is rather strong, the in perpetuity cost should be seen as a rough estimate of funds required to maintain the collection for future generations. Given an annual cost of the AVRDC genebank of USD 683,548 and a real interest rate of $4 \%$, as assumed by most previous genebank costing studies, the endowment would have to be USD 17.1 million to maintain the present collection (Table 5).

However, the collection has grown at an average rate of $1.87 \%$ per annum over the past 18 years. If we incorporate this growth in our calculation and assume that the current cost per accession would remain unchanged, then the size of the genebank endowment fund would have to be USD 32.1 million. ${ }^{5}$ The table shows that these figures are highly sensitive to assumed interest rate, but they are equally sensitive to the assumed growth rate of the collection.

\section{Discussion}

Comparison to the five major CGIAR genebanks

This section compares the costing of the AVRDC genebank with that of the five largest genebanks of the CGIAR as reported by Koo et al. (2004) and shown in Table 6. It is noted that a strict comparison is not possible because different crops have different conservation requirements, the cost of inputs is different in each location, and data refer to different years (though all values were converted to 2012 values).

The replacement value (or present value) of the AVRDC genebank facilities and equipment of 2.5

5 The required present value of the fund $=$ Current annual cost $/$ ((interest rate - growth rate of the collection)/100). 
Table 4 Annual average cost per processed accession per genebank operation, in US dollar/year

\begin{tabular}{lclll}
\hline Genebank operation & Total cost & $\begin{array}{l}\text { Accessions processed } \\
\text { in reference year }\end{array}$ & $\begin{array}{l}\text { Cost per accession } \\
\text { processed }\end{array}$ & $\begin{array}{l}\text { Cost per all } \\
\text { accessions }\end{array}$ \\
\hline Acquisition & 14,519 & 1,024 & 14.18 & 0.21 \\
Characterization & 66,439 & 1,342 & 49.51 & 18.24 \\
Dissemination (or distribution) & 85,551 & 4,690 & 1.19 & 1.98 \\
General management & 80,673 & 67,817 & 104.1 & 1.26 \\
Germination/viability testing & 6,142 & 59 & - & 0.09 \\
In vitro conservation & 1,818 & 0 & 0.61 & 0.03 \\
Information and data management & 41,111 & 67,817 & 1.34 & 0.61 \\
Long-term storage & 47,291 & 22,952 & 0.65 & 0.70 \\
Medium-term storage & 43,909 & 67,817 & 2.96 & 0.65 \\
Short-term storage & 25,983 & 14,278 & 64.43 & 0.38 \\
Regeneration & 139,500 & 2,165 & 9.67 & 2.06 \\
Safety/security duplication & 17,573 & 1,817 & 62.21 & 0.26 \\
Seed processing & 113,040 & 1,817 & - & 1.67 \\
Total & 683,548 & - & 10.08 \\
\hline All & & & & \\
\hline
\end{tabular}

All values in 2012 value terms

a In vitro conservation was not practiced in 2012 though facilities are available and hence there is a capital cost

Table 5 Total cost of germplasm conservation and dissemination in perpetuity at alternative interest rate assumptions, in million US dollars

\begin{tabular}{|c|c|c|c|c|c|c|c|}
\hline \multirow[t]{3}{*}{ Cost type } & \multirow[t]{3}{*}{ Current annual cost } & \multicolumn{3}{|c|}{ For maintaining the current collection } & \multicolumn{3}{|c|}{ For an expanding collection ( $1.87 \%$ per annum) } \\
\hline & & \multicolumn{3}{|c|}{ Real interest rate } & \multicolumn{3}{|c|}{ Real interest rate } \\
\hline & & $2(\%)$ & $4(\%)$ & $6(\%)$ & $2(\%)$ & $4(\%)$ & $6(\%)$ \\
\hline Capital & 0.107 & 5.34 & 2.67 & 1.78 & 82.12 & 5.01 & 2.58 \\
\hline Quasi-fixed & 0.456 & 22.82 & 11.41 & 7.61 & 351.04 & 21.43 & 11.05 \\
\hline Variable labor & 0.049 & 2.46 & 1.23 & 0.82 & 37.88 & 2.31 & 1.19 \\
\hline Variable non-labor & 0.071 & 3.56 & 1.78 & 1.19 & 54.77 & 3.34 & 1.72 \\
\hline Total & 0.684 & 34.18 & 17.09 & 11.39 & 525.81 & 32.09 & 16.55 \\
\hline
\end{tabular}

million USD is slightly above the range of the other genebanks (from USD 1.6 million for ICARDA to USD 2.3 million for CIMMYT). This is perhaps because of the recent renovation and extension of the AVRDC genebank, which accounts for $31 \%$ of the replacement value. The current capacity is enough to expand the current collection to nearly twice its present size. However, in terms of annualized capital cost (USD 0.107 million/year), the AVRDC genebank is well within the range of the other five genebanks, which range from USD 0.103 million for ICARDA to USD 0.155 million for IRRI.

Of the five genebanks, the annual cost of the AVRDC genebank (USD 0.7 million) is the second lowest. In comparison, CIAT's annual cost is 1.2 million and CIMMYT's is 1.0 million. However, it is noted that the $e x$ situ conservation of seed producing crops, and particularly self-pollinating ones, is much cheaper than that of crops which require both in vitro and field conservation as is the case for cassava at CIAT.

As for the other genebanks, capital costs only make a minor contribution to the total annual cost of the AVRDC genebank. Genebanks are more labor- than capital-intensive. Labor costs contribute $74 \%$ of the total annual costs at AVRDC, which is more than for the other genebanks. Being the only genebank in our comparison located in a high-income country, wages are relatively high. 
Table 6 Comparison of the cost of the AVRDC genebank to five other genebanks, in 2012 US dollar values

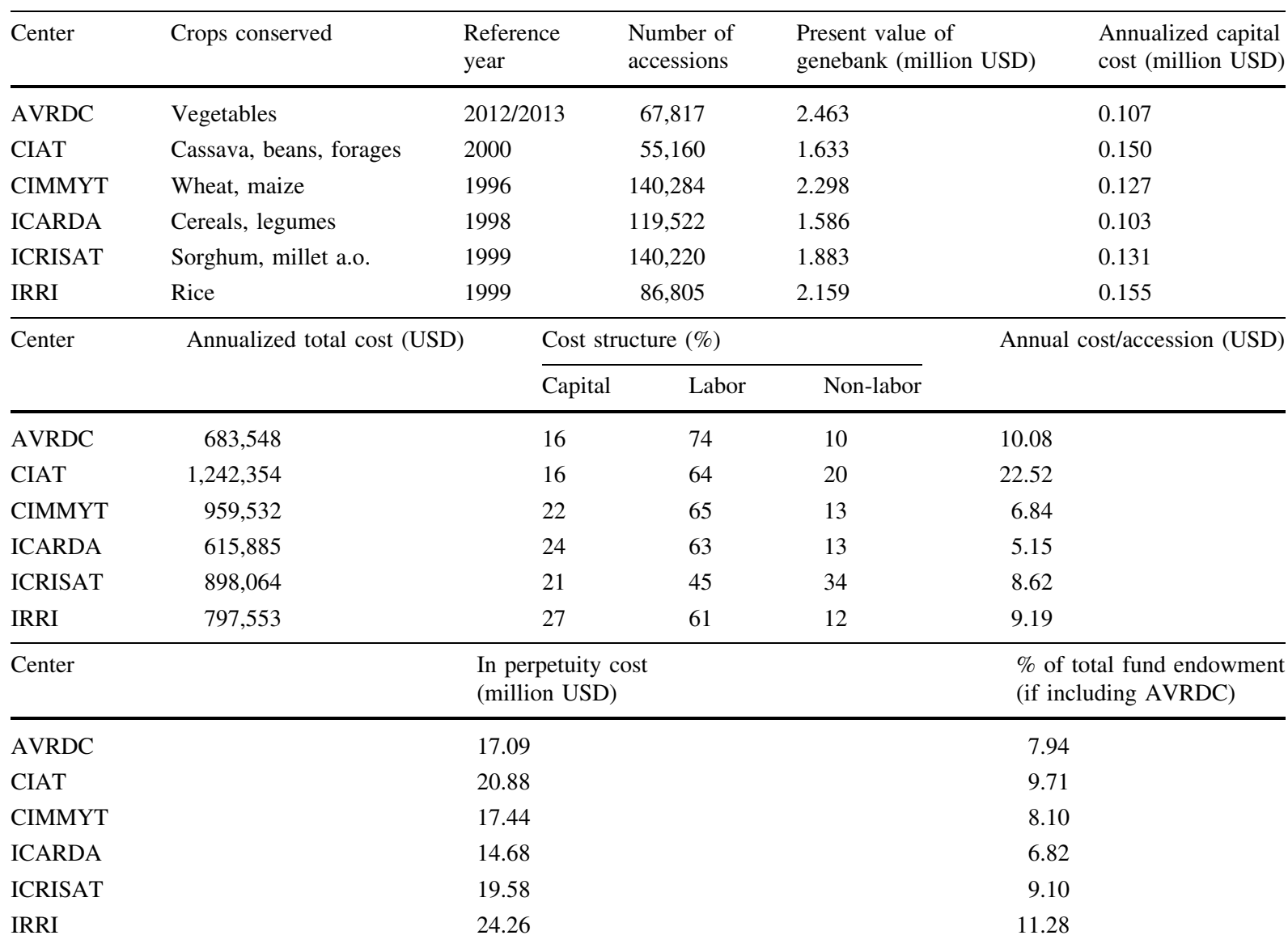

All US dollar values for the CGIAR genebanks were converted to 2012 values using consumer price index values for the United States

To compare the average cost per accession we divided the total annual cost of each genebank by the total number of accessions. The average cost of germplasm conservation and dissemination is USD 10.08 per accession, which is within the range of values for the other genebanks. For instance, the cost per accession is USD 5.15 for ICARDA and USD 22.52 for CIAT.

Lastly, in terms of the required endowment for maintaining the current collection in perpetuity, the size of such fund would be USD 17.1 million for AVRDC, the second lowest value in the comparison. ICARDA would require USD 14.7 million, while IRRI would require USD 24.3 million. Koo et al. (2004) (p. 137) suggested that the total fund requirement for the entire CGIAR would be USD 148.6 million in 2000 (USD 198.1 million in 2012 value terms). Including the AVRDC genebank as part of the fund would require the fund endowment to expand by $8.6 \%$ to USD 215.2 million (2012 value terms).

Current challenges in managing the AVRDC collection

A recent project supported by the Global Crop Diversity Trust from July 2008 to February 2012 provided a major boost for the regeneration and characterization efforts of AVRDC. Despite these efforts, there is still a major backlog in species regeneration and characterization. Particularly for the genera Cucurbita and Vigna, there is a backlog of over $70 \%$ of the accessions held. Many other collections also will require major effort in the near future to safeguard them and to make high quality seed of wellcharacterized accessions available to breeders worldwide. In total, we estimate that nearly 27,000 
accessions are overdue for regeneration and characterization. Based on the average regeneration and characterization cost per processed accession, the required funds for eliminating the present backlog would be USD 1.72 million for regeneration and USD 1.28 million for characterization, hence USD 3.00 million in total. Eliminating the present backlog in 10 years would therefore require an additional funding of USD 300,000/year.

\section{Seed processing and shipment fees}

Given the crucial role that genebanks play in plant breeding and crop research, and consequently in ensuring long-term global food and nutrition security, especially under climate change scenarios and the funding constraints many genebanks face, it is highly relevant that genebank managers consider the introduction of handling and shipping fees for the distribution of genebank samples. ${ }^{6}$ Only very few public genebanks have so far actually introduced handling fees, notably the National Institute of Agrobiological Sciences, Japan and AVRDC.

Charging a handling fee can help offset seed shipment costs and can motivate customers to more critically assess their actual need for an accession. As a result, some users might decide not to request material or try to get the same or similar material from another genebank not charging such fees. Such a reduction in sample requests would be positive if it reduces illconsidered requests or requests for excessive numbers of genebank accessions; however, it may also deter some users from developing countries from requesting material, which would run counter to the genebank's mandate to promote the use of its materials. The willingness of users to collaborate with the genebank in giving feedback and sending evaluation data back to the genebank may also be negatively affected.

In April 2009, AVRDC started charging seed processing and shipment fees to support routine genebank operations. The fee structure distinguishes between (a) public sector institutions in developing

\footnotetext{
${ }^{6}$ The Centre for Genetic Resources (CGN), Wageningen, the Netherlands recently initiated a discussion in the international genebank community on the introduction of handling fees due to deficiencies in the funding for the operations of the CGN genebank (http://agro.biodiver.se/2012/06/would-you-pay-e50per-accession/; accessed on 30 April 2013).
}

countries (National Agricultural Research and Extension Systems and universities), and (b) advanced research institutes and universities in developed countries and the private sector worldwide. Public sector institutions in developing countries pay a lump sum of USD 30 for the first 15 genebank accessions or breeding lines, USD 6 for each additional accession, and USD 20 for each additional breeding line. We observed many requests of 15 lines per order per year, presumably only to pay the minimum fee; requesters would then wait 1 year before submitting their next order for another 15 lines. It is problematic for some public institutions in developing countries to pay the fees at all. In addition, bank charges are often an issue, especially if the order was only for USD 30; the receiving bank charges USD 25 in fees which has to be paid by the client, while their own bank may also charge fees. ${ }^{7}$

Advanced research institutes and universities in developed countries and the private sector have to pay USD 30 per genebank accession and USD 50 per breeding line. In terms of immediate use value for the private sector, breeding lines are, of course, much more valuable than genebank accessions (the potential of which some breeders consider to be about the same as a lottery ticket). Only a few companies complained about the cost of the breeding lines as they know their true value. AVRDC's mostly open-pollinated vegetable breeding lines, characterized by multiple disease resistance and other outstanding quality traits, are in some cases directly used for commercialization by seed companies or, in the majority of cases, after crossing with one or several company lines to produce hybrid lines for sale.

Our analysis for this study showed that the cost of distributing seed for 4,690 accessions was USD 85,551 or USD 1.26 per accession. Postage and DHL delivery charges for seed shipment amounted to USD 3,879, while most other costs were labor costs, packaging materials and labels. Returns from seed shipment fees amounted to USD 71,700 during the reference period and hence covered $83.8 \%$ of the seed distribution costs.

The number of genebank accessions and breeding lines requested, however, showed a marked decrease since the introduction of the fees. It reduced during the

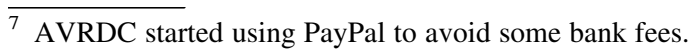




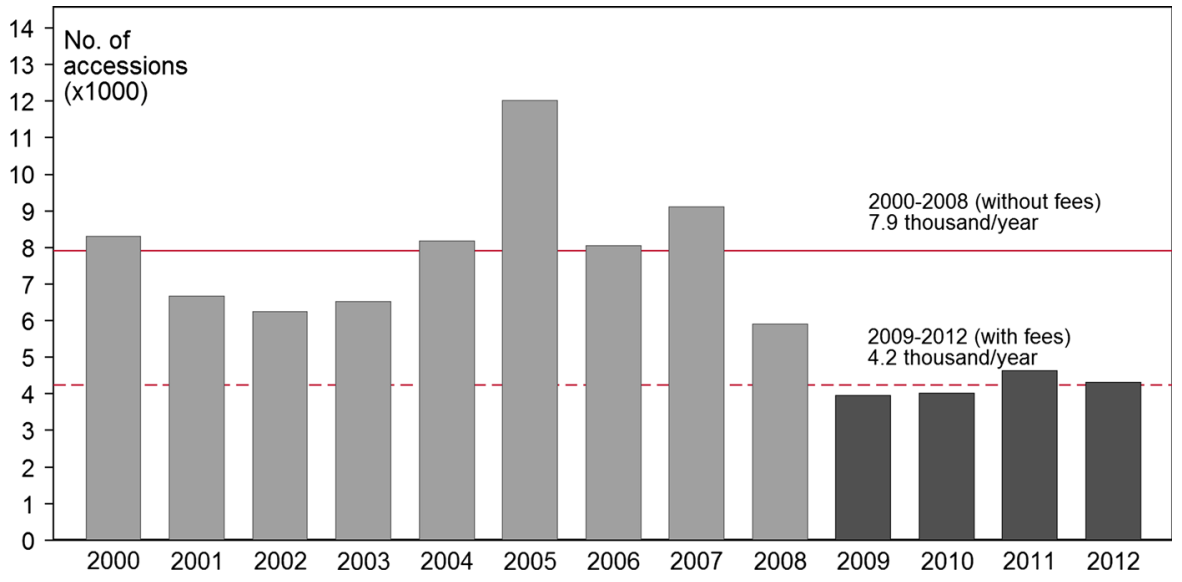

Fig. 4 Annual distribution of genebank accessions and improved lines to non-AVRDC researchers and breeders, 2000-2012

period from 2009 to 2012 by $46.4 \%$ compared to the average yearly requests during the preceding 9 years (Fig. 4). Seed distribution has not shown significant variation since the introduction of the fee structure with an average of 4,237 accessions and breeding lines distributed externally per annum from 2009 to 2012. On the positive side, the introduction of fees discouraged frivolous requests of hundreds of lines of a single crop by single clients - an amount of lines which is costly for AVRDC to provide and difficult for the recipient to effectively use in germplasm screening trials.

About the genebank costing tool

The Decision Support Tool (DST) based on the genebank costing methodology developed by Koo et al. (2004) was useful in giving a clear structure to the calculations by dividing genebank activities into 15 operations and costs into four categories. It furthermore helped to ensure some degree of comparability with previous studies, though there are several other caveats to consider.

The difficulty in applying the DST to the AVRDC genebank was the diversity of germplasm held at AVRDC. While CIMMYT, for instance, has two clearly distinct collections of wheat and maize, each with its own staff and resources, the AVRDC collections are managed jointly with resources used for all collections and staff members work on several collections at the same time. Disaggregating staff working time and facility areas to specific crops and operations could therefore not be done in a precise manner. The disaggregation might also be less relevant for the AVRDC genebank as most vegetable crops produce orthodox seeds (except shallot-Allium cepa $\mathrm{L}$. var. aggregatum $\mathrm{G}$. Don and garlic-Allium sativum L. var. sativum) and the costs are therefore similar. A further aggregation of crops into wider categories therefore seems advisable for future use of the tool.

An important improvement to the tool would be if it had the ability to enter data from various years in one file so that entries could be easily compared and changes to the cost structure could be made visible. Horna (2010: 19) also suggested this improvement for a future version of the tool. Since labor and capital costs will not change much over time, repeating the study for subsequent years will be useful for monitoring purposes but might not give additional insights into the cost structure of the genebank.

\section{Conclusion}

The ex situ conservation of plant genetic resources at AVRDC - The World Vegetable Center in Taiwan costs USD 0.684 million/year. Of these costs, $74 \%$ is for temporary and permanent labor while facilities and equipment account for $16 \%$. We did not find marked differences in the average cost per accession for the major collections held in the genebank because of difficulties in disaggregating costs to different crops. The annual cost of disseminating and distributing genebank accessions was USD 85,551 and $84 \%$ of 
these costs were recovered by seed processing and shipment fees that have been in effect since 2009.

Annualized capital costs of the AVRDC genebank are the second lowest compared with those of the five major CGIAR genebanks. However, the average total cost per genebank accession is USD 10.08, which is the second highest compared with other genebanks and is probably due to relatively high labor costs in Taiwan.

More stable funding mechanisms are needed to enhance the global role of the AVRDC genebank. Maintaining the current AVRDC collection in perpetuity would require an endowment of USD 17.1 million, assuming a real interest rate of $4 \%$ per annum. Assuming that the $1.9 \%$ growth in number of accessions as experienced over the past 18 years continues, then the endowment would have to be USD 32.1 million. Although seemingly high, these costs are small compared to the past and future benefits from vegetable crop improvement.

Acknowledgments The authors acknowledge the effort made by the GRSU staff for this study-Yung-kuang Huang, Chinghuan Chang, Miao-rong Yan, Yu-yu Chou, Tien-hor Wu, Sheng-hung Yen, and Li-hsueh Lin. We also acknowledge the technical support received from Daniela Horna for using the costing tool, Maureen Mecozzi for editing the text, and Dirk Overweg, Jacqueline d'Arros Hughes and Dyno Keatinge for their helpful comments on an earlier version of this paper. We thank two anonymous reviewers of this journal for their constructive comments.

Open Access This article is distributed under the terms of the Creative Commons Attribution License which permits any use, distribution, and reproduction in any medium, provided the original author(s) and the source are credited.

\section{References}

AVRDC (2013). AVRDC-The World Vegetable Center Year in Review 2012. AVRDC-The World Vegetable Center, Shanhua, Tainan, Taiwan, p 20

de la Peña RC, Ebert AW, Gniffke P, Hanson P, Symonds RC (2011) Chapter 18. Genetic adjustment to changing climates: vegetables. In: Yadav SS, Redden RJ, Hatfield JL, Lotze-Campen H \& Hall AE (eds) Crop Adaptation to Climate Change, First Edition. Wiley, Chichester, West Sussex, UK, pp 396-410

Ebert AW (2011) Vegetable germplasm conservation and utilization at AVRDC-The World Vegetable Center. Proc Vth IS Seed Transpl Stand Establishment Hort Crops Acta Hort 898:89-95
Ebert AW (2013) Chapter 16-ex situ conservation of plant genetic resources of major vegetables. In: Normah MN, Chin HF, Reed BM (eds) Conservation of tropical plant species. Springer Science + Business Media, New York, pp 373-417. doi:10.1007/978-1-4614-3776-5_2

FAO (2010) The second report on the state of the world's plant genetic resources for food and agriculture. Rome

FAO (2013) Genebank standards for genetic resources for food and agriculture. Rome

Frison EA, Cherfas J, Hodgkin T (2011) Agricultural biodiversity is essential for a sustainable improvement in food and nutrition security. Sustainability 3:238-253

Horna D (2010) Guide for users: decision support tool. International Food Policy Research Institute, Washington, DC

Jackson LE, Pascual U, Hodgkin T (2007) Utilizing and conserving agrobiodiversity in agricultural landscapes. Agric Ecosys Environ 121:196-210

Keatinge JDH, Hughes J d'A, Ebert A, Ledesma D, Luther K, de la Peña R, Javier E (2008) Preserving the future of vegetable improvement. In: Huang S-C, Chen S (eds) Capacity building for development and implementation of risk management systems on genetic resources. Proceedings of the APEC-ATCWG Workshop, 14-17 October 2008, Taichung, Taiwan. ARI Special Publication No. 135, pp 21-34

Koo B, Pardey PG, Wright BD (2002) Endowing future harvests: the long-term costs of conserving genetic resources at the CGIAR centres. International Plant Genetic Resources Institute, Rome

Koo B, Pardey P, Wright B (2003a) The price of conserving agricultural biodiversity. Nat Biotechnol 21:126-128. doi: $10.1038 /$ nbt0203-126

Koo B, Pardey PG, Wright BD (2003b) The economic costs of conserving genetic resources at the CGIAR centres. Agric Econ 29:287-297. doi:10.1016/S0169-5150(03)00056-2

Koo B, Pardey PG, Wright BD, Bramel P, Debouck D, van Dusen ME, Jackson MT, Rao NK, Skovmand B, Taba S, Valkoun J (2004) Saving seeds: the economics of conserving crop genetic resources ex-situ in the future harvest centres of the CGIAR. CABI Publishing, Oxfordshire

McCouch S (2013) Feeding the future. Nature 499:23-24

Mecozzi M, Ebert AW (2012) At this bank for vegetables, withdrawals produce interest. DFID case study on AVRDC Genebank. AVRDC-The World Vegetable Center. 7 February 2012, p 7

Pardey PG, Koo B, van Dusen ME, Skovmand B, Taba S (2001) Costing the conservation of genetic resources: CIMMYT's ex situ maize and wheat collection. Crop Sci 41:1286-1299

RDA (2008) Global seed hub declaration ceremony, 30-31 October 2008, National Agrobiodiversity Center, Rural Development Administration (RDA), Republic of Korea

Stamp P, Messmer R, Walter A (2012) Competitive underutilized crops will depend on the state funding of breeding programmes: an opinion on the example of Europe. Plant Breed 131:461-464

UNEP (2011) Keeping track of our changing environment: from Rio to Rio + 20 (1992-2012). Division of Early Warning and Assessment (DEWA), United Nations Environment Programme (UNEP), Nairobi, Kenya, p 99 
Van Treuren R, de Groot EC, van Hintum JL (2013) Preservation of seed viability during 25 years of storage under standard genebank conditions. Genet Resour Crop Evol 60(4):1407-1421
WWF (2010) Living Planet Report 2010: Biodiversity, biocapacity and development. World Wildlife Fund, Gland, Switzerland, p 55 